\title{
Formation of Flower-Like Crystals of Tris(8-hydroxyquinoline)aluminum from 8-Hydroxyquinoline on Anodic Porous Alumina
}

\author{
Shohei Yamaguchi, ${ }^{1}$ Tomohiro Iida, ${ }^{2}$ and Kazunori Matsui ${ }^{2}$ \\ ${ }^{1}$ Graduate School of Engineering, Kanto Gakuin University, 1-50-1 Mutsuurahigashi, Kanazawa-ku, \\ Yokohama, Kanagawa 236-8501, Japan \\ ${ }^{2}$ College of Science and Engineering, Kanto Gakuin University, 1-50-1 Mutsuurahigashi, Kanazawa-ku, Yokohama, \\ Kanagawa 236-8501, Japan \\ Correspondence should be addressed to Kazunori Matsui; matsui@kanto-gakuin.ac.jp
}

Received 7 March 2017; Accepted 13 April 2017; Published 7 May 2017

Academic Editor: Kohji Tashiro

Copyright (C) 2017 Shohei Yamaguchi et al. This is an open access article distributed under the Creative Commons Attribution License, which permits unrestricted use, distribution, and reproduction in any medium, provided the original work is properly cited.

The treatment of anodic porous alumina (APA) plates in heated water containing 8-hydroxyquinoline (HQ) produces crystalline tris(8-hydroxyquinoline)aluminum $\left(\mathrm{Alq}_{3}\right)$ microbelts about 5-10 $\mu \mathrm{m}$ wide and 5-20 $\mu \mathrm{m}$ long. These microbelts were found to aggregate to form flower-like structures on the surface. X-ray diffraction studies indicated that the $\mathrm{Alq}_{3}$ microbelts are composed of an $\alpha$-phase having a meridional structure. The $\mathrm{Alq}_{3}$ microbelts exhibited green photoluminescence with a peak at around $520 \mathrm{~nm}$. Scanning electron microscope images and energy dispersive $\mathrm{X}$-ray spectra showed that this reaction is induced at the APA surface by the reaction between the $\mathrm{HQ}$ and amorphous $\mathrm{Al}_{2} \mathrm{O}_{3}$ species.

\section{Introduction}

Since the pioneering report in 1987 by Tang and Van Slyke [1] on efficient green electroluminescence using tris $(8-$ hydroxyquinoline)aluminum $\left(\mathrm{Alq}_{3}\right), \mathrm{Alq}_{3}$ has been adopted as an important electron transport layer as well as a vital light-emitting material for organic light-emitting diodes. The preparation and characterization of $\mathrm{Alq}_{3}$ have been widely studied [2-20]. Because of the bidentate ligand, $\mathrm{Alq}_{3}$ complexes form two isomers, as shown in Figure 1: meridional and facial. Interestingly, the two isomers exhibit different types of photoluminescence (PL): specifically, green $[2,3]$ in the case of the meridional isomer and blue [4-7] for the facial isomer. To date, five crystalline phases $(\alpha, \beta, \gamma, \delta$, and $\varepsilon)$ have been identified for $\mathrm{Alq}_{3}[8-10]$. To the best of our knowledge, $\alpha$ , $\beta$-, and $\varepsilon-\mathrm{Alq}_{3}$ are formed by meridional isomers, while $\gamma$ and $\delta-\mathrm{Alq}_{3}$ are formed by facial isomers [2, 5-7, 10-13].

Moreover, $\mathrm{Alq}_{3}$ crystals with a wide range of morphologies have been prepared, including nanoparticles produced by vapor condensation [14], nanowires produced using either a single-step heat treatment [15] or an adsorbentassisted physical vapor deposition (PVD) process [16], pine needle-like crystals produced by PVD [3], and nanorods produced by solution synthesis with a surfactant [17]. All of these $\mathrm{Alq}_{3}$ crystals demonstrate interesting morphologydependent properties. For example, the $\mathrm{Alq}_{3}$ nanoparticles prepared by vapor condensation were amorphous and the maximum PL intensity at about $538 \mathrm{~nm}$ increased as the average particle size decreased [14]. These same $\mathrm{Alq}_{3}$ nanoparticles can be heat treated and grown into the $\alpha-\mathrm{Alq}_{3}$ nanowires via the $\gamma$-Alq $q_{3}$ phase [15]. When $\mathrm{Alq}_{3}$ nanowires were fabricated by heating mixtures of silica gel and $\mathrm{Alq}_{3}$, they exhibited a blue shift in the absorption spectra with decreasing nanowire diameter, and the photoluminescence vibrational fine structure intensified with increasing excitation energy [16]. Besides nanoparticles and nanowires, pine needle-like crystals with an $\varepsilon$-Alq ${ }_{3}$ phase were prepared by $\mathrm{PVD}$ in a double zone tube furnace [3]. Another $\alpha-\mathrm{Alq}_{3}$ 


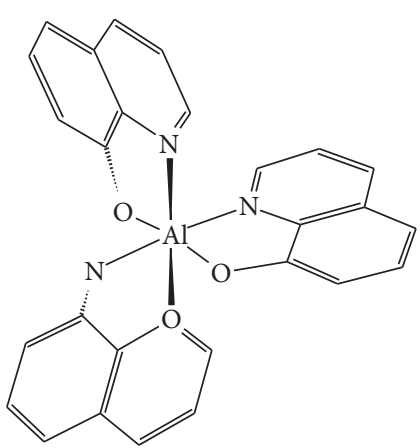

(a)

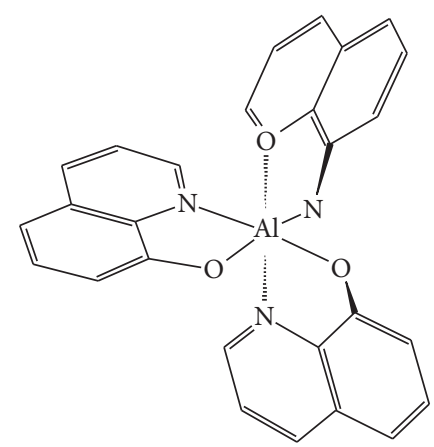

(b)

FIgURE 1: Structures of $\mathrm{Alq}_{3}$ isomers: meridional (a) and facial (b).

crystal morphology comprises nanorods, which have a regular hexagonal shape when prepared by self-assembly growth assisted by surfactants, and these exhibited suitable field emission characteristics [17]. A different fabrication technique in which 8-hydroxyquinoline (HQ) and $\mathrm{Alq}_{3}$ were dissolved in an ethanol/water solution and then exposed to highintensity ultrasound irradiation resulted in the formation of well-defined $\mathrm{Alq}_{3}$ nanoflowers $\left(\alpha-\mathrm{Alq}_{3}\right)$ [18]. Since each particular structure of $\mathrm{Alq}_{3}$ exhibits unique optoelectronic properties that may be adopted for various nanodevice applications, it would be extremely interesting to explore additional novel fabrication methods capable of controlling the isomer formation, crystal structure, and/or morphology of $\mathrm{Alq}_{3}$ crystals.

In recent years, anodic porous alumina (APA) has attracted significant attention in various nanotechnology areas, including light-emitting devices [21]. As a result, there have been many studies of APA composites with highly fluorescent $\mathrm{Alq}_{3}$ [22-26]. In a previous study, we reported that $\mathrm{Alq}_{3}$ was formed on APA immersed in an ethanol solution of 8-hydroxyquinoline (HQ) at $60^{\circ} \mathrm{C}$ [27]. The PL spectra showed two peaks at wavelengths of 480 and $505 \mathrm{~nm}$, which were attributed to isolated $\mathrm{Alq}_{3}$ inside the nanovoids and aggregated $\mathrm{Alq}_{3}$ in the nanopores of the APA, respectively. The formation mechanism of the $\mathrm{Alq}_{3}$ was considered to be due to the reaction of the HQ with the $\mathrm{Al}^{3+}$ ions in the oxide dissolution zone and the $\mathrm{Al}^{3+}$ ions adsorbed onto the surfaces of the pores and cracks.

In the present study, we continued to investigate similar reactions in boiling water containing HQ and APA and found that an $\alpha$-crystalline-phase of $\mathrm{Alq}_{3}$ microbelts self-assembles on the APA plates in flower-like structures. This study characterizes the crystalline and optoelectronic properties of these unique structures.

\section{Experimental}

2.1. Preparation of APA Samples. An Al plate (99.59\% purity, Nilaco Co., $1 \mathrm{~cm}^{2}$ ) was electropolished in a mixed solution of $60 \%$ perchloric acid and $99.5 \%$ ethanol $(1: 4 \mathrm{v} / \mathrm{v})$ at a constant voltage of $20 \mathrm{~V}$ below $5^{\circ} \mathrm{C}$ for $40 \mathrm{~s}$. Then, the APA sample was prepared by either one- or two-step anodization.
One-step anodization was carried out in $0.3 \mathrm{M} \mathrm{H}_{2} \mathrm{SO}_{4}$ at $20 \mathrm{~V}$ and at room temperature for $30 \mathrm{~min}$. For the two-step process, anodization was carried out under similar conditions for $10 \mathrm{~min}$. Then, the anodized plate was immersed in a mixed solution of $6.0 \mathrm{wt} \% \mathrm{H}_{3} \mathrm{PO}_{4}$ and $1.8 \mathrm{wt} \% \mathrm{H}_{2} \mathrm{CrO}_{4}$ at $70^{\circ} \mathrm{C}$ for $15 \mathrm{~min}$. The plate was then anodized for a second time under the same conditions for $30 \mathrm{~min}$.

2.2. Formation of $\mathrm{Alq}_{3}$ on APA Surface. The APA samples were placed in a beaker with distilled water containing HQ under various conditions (i.e., concentration, time, and temperature) and then dried in air at room temperature after being removed from the beaker. Observations of the appearance of the surfaces after drying were noted.

2.3. Instrumental Analysis. Scanning electron microscope (SEM) images and energy dispersive X-ray (EDX) spectra were observed by a Quanta 3D 200i scanning electron microscope (FEI) equipped with an EDX analyzer (EDAX). To observe a cross-section, $\mathrm{Alq}_{3}$ microbelts formed on a twostep APA surface were cut by a $\mathrm{Ga}^{+}$focused ion beam. The Xray diffraction patterns (XRD) were measured using a RINT 2200 (Rigaku) with $\mathrm{Cu} \mathrm{K} \alpha$ radiation. The PL spectra were measured using an FP-8500 fluorescence spectrophotometer (JASCO) with an ISF-834 integrated sphere unit, excited at $370 \mathrm{~nm}$.

\section{Results and Discussion}

3.1. Effect of Anodization Process on Crystal Morphology and Crystalline Phase. After APA was placed in a beaker with distilled water and HQ at various concentrations, times, and temperatures and then dried, visual observations of the surfaces of the APA were made. The upper APA surface was deep yellow (due to $\mathrm{Alq}_{3}$, which will be proved later), but the underside of the plate, where the APA was touching the beaker, was a paler yellow.

Figure 2 shows typical SEM images of crystals on the one-step (a) and two-step (b) APA surfaces treated in a $10 \mathrm{mM} H Q$ solution at $100^{\circ} \mathrm{C}$ for $3 \mathrm{~min}$. Belt-like structures, about $5 \mu \mathrm{m}$ wide and $20-30 \mu \mathrm{m}$ long, are formed by the one-step process. The microbelts appear to self-assemble into 


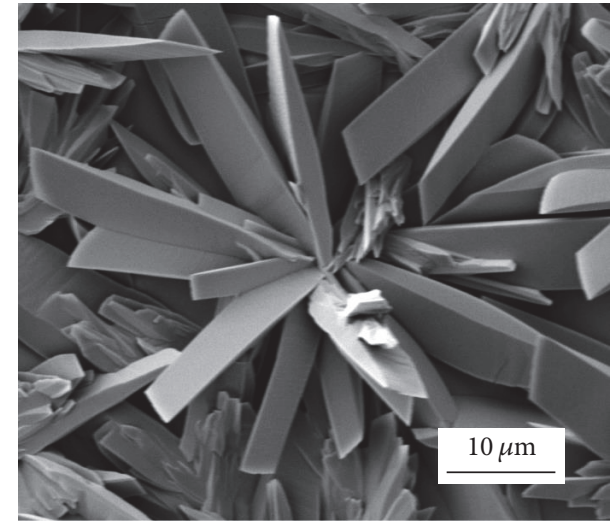

(a)

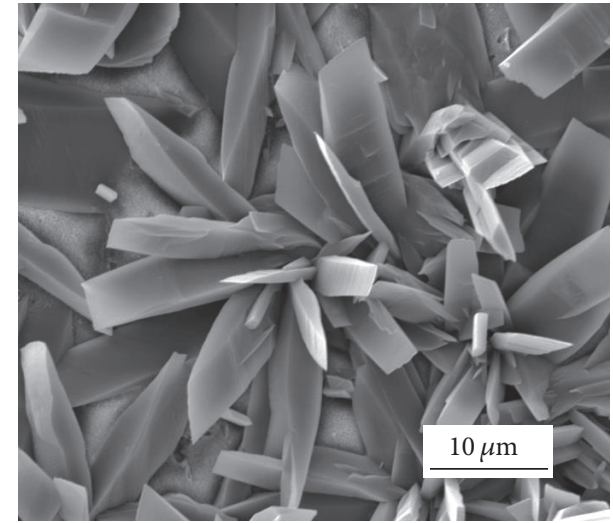

(b)

FIgURE 2: SEM images of the $\mathrm{Alq}_{3}$ microbelts on the one-step (a) and two-step (b) APA surface. The crystals were formed by treating the APA samples in a $10 \mathrm{mM} H Q$ solution at $100^{\circ} \mathrm{C}$ for $3 \mathrm{~min}$.

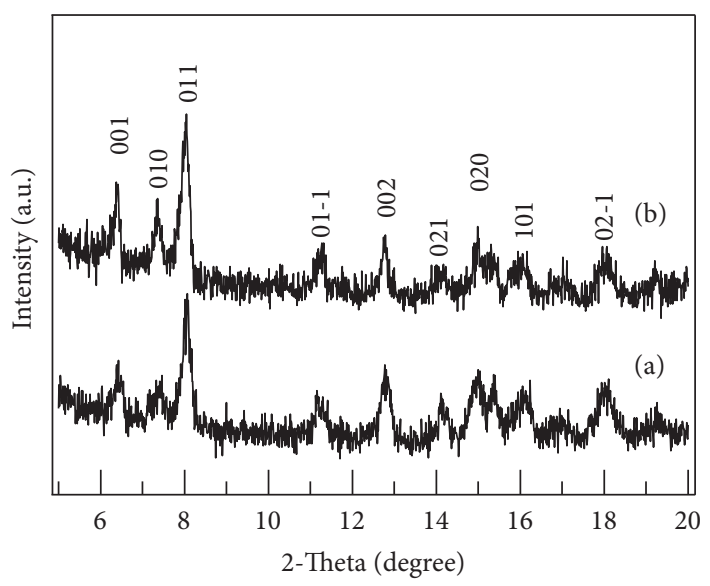

FIGURE 3: XRD patterns of $\mathrm{Alq}_{3}$ microbelts on the one-step (a) and two-step (b) APA surface. The crystals were formed by treating the APA samples in a $10 \mathrm{mM} H Q$ solution at $100^{\circ} \mathrm{C}$ for $3 \mathrm{~min}$.

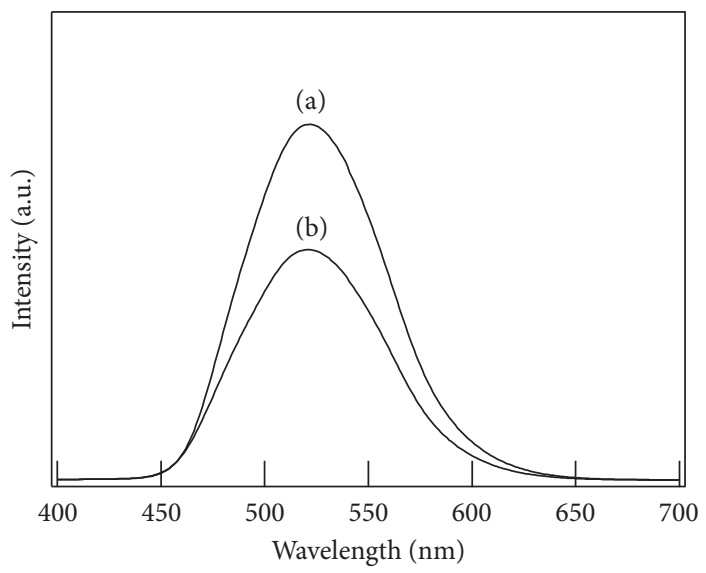

FIGURE 4: PL spectra of $\mathrm{Alq}_{3}$ microbelts on the one-step (a) and two-step (b) APA surface. The crystals were formed by treating the APA samples in a $10 \mathrm{mM} H Q$ solution at $100^{\circ} \mathrm{C}$ for $3 \mathrm{~min}$. The excitation wavelength was $370 \mathrm{~nm}$. 


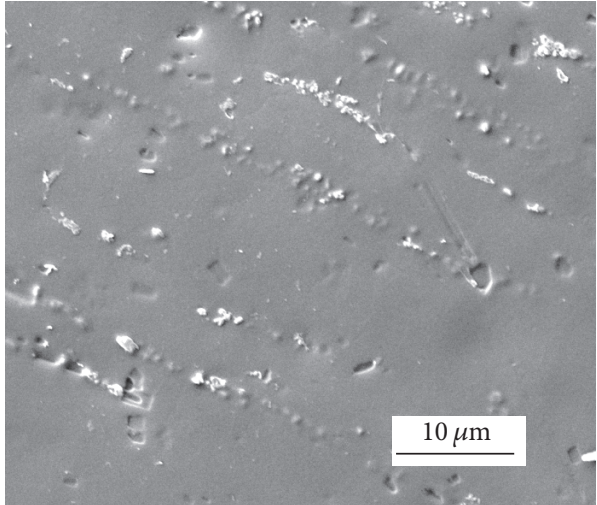

(a)

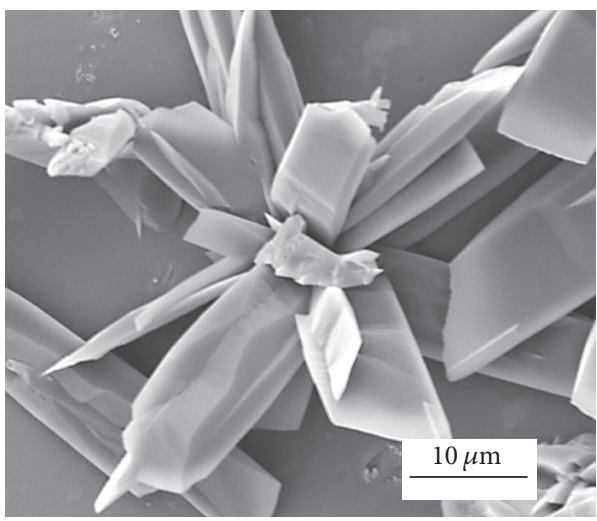

(c)

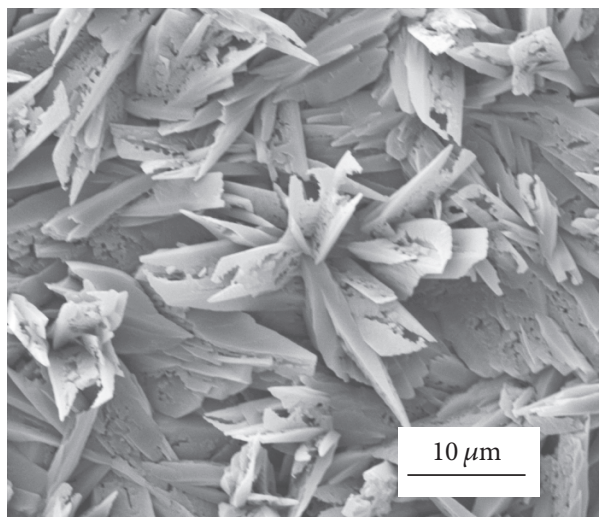

(e)

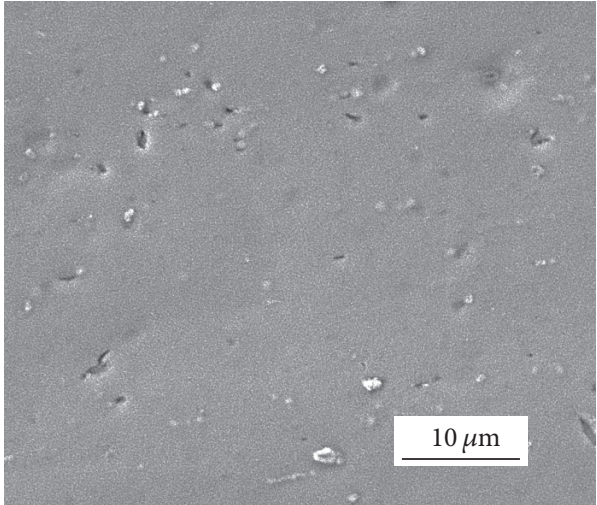

(b)

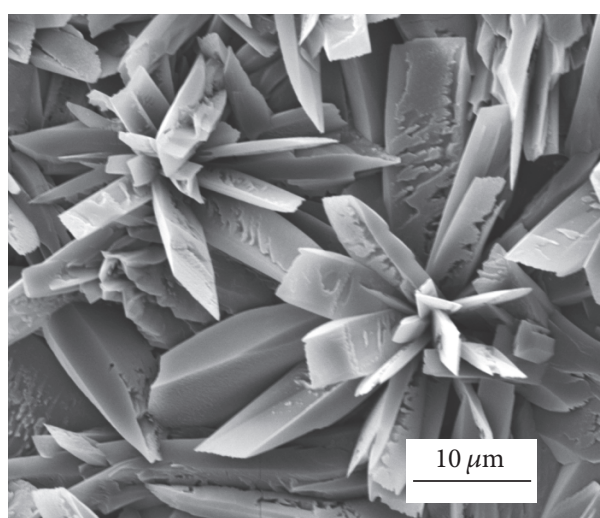

(d)

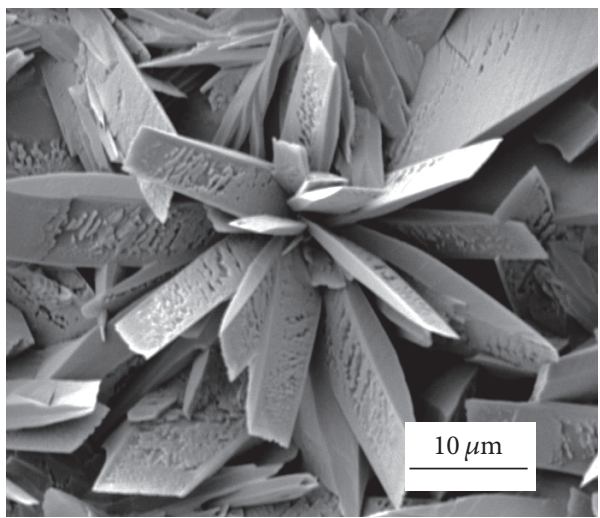

(f)

FIGURE 5: SEM images of as-prepared one-step APA sample (a) and samples treated at $100^{\circ} \mathrm{C}$ for 10 min in HQ solutions of different concentrations: $1 \mathrm{mM}$ (b), $3 \mathrm{mM}$ (c), $5 \mathrm{mM}$ (d), $7 \mathrm{mM}$ (e), and $10 \mathrm{mM}$ (f).

flower-like structures. For the two-step process, the belt-like structures were shorter, having a width of about $5 \mu \mathrm{m}$ and a length of $10-20 \mu \mathrm{m}$.

Figure 3 shows the XRD patterns for the microbelts in Figure 2. The XRD patterns for both the one-step and two-step processes have essentially the same patterns and agree with those of the $\alpha-\mathrm{Alq}_{3}$ powders previously reported by Brinkmann et al. [2], Braun et al. [4], and Kaji et al. [8], who confirmed that the microbelts consist of $\alpha-\mathrm{Alq}_{3}$ regardless of the anodizing conditions. In a previous study, Katakura and Koide [10] reported that the treatment of boehmite, $\mathrm{AlO}(\mathrm{OH})$, with $\mathrm{HQ}$ in boiling water produces either $\alpha-\mathrm{Alq}_{3}$ or $\gamma-\mathrm{Alq}_{3}$ depending on whether the reaction is allowed to continue for $1 \mathrm{~h}$ or $90 \mathrm{~h}$, respectively. Tsuboi and Torii [28] also reported that the reaction of aluminum hydroxide, $\mathrm{Al}(\mathrm{OH})_{3}$, with HQ forms $\alpha$ - $\mathrm{Alq}_{3}$ and $\gamma$-Alq $\mathrm{A}_{3}$ after a reaction time of $24 \mathrm{~h}$ and $100 \mathrm{~h}$, respectively. Our XRD results agree with these previous studies at relatively short 


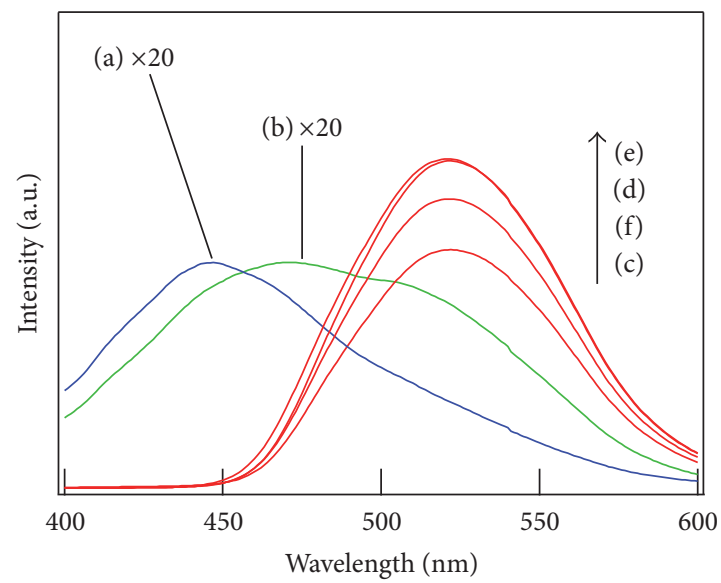

FIGURE 6: PL spectra of as-prepared APA sample (a) and the samples treated in HQ solutions at $100^{\circ} \mathrm{C}$ for 10 min with different concentrations: $1 \mathrm{mM}$ (b); $3 \mathrm{mM}$ (c); $5 \mathrm{mM}$ (d); $7 \mathrm{mM}$ (e); and $10 \mathrm{mM}$ (f). The excitation wavelength was $370 \mathrm{~nm}$.

reaction times. Specifically, the reaction of APA with HQ at $100^{\circ} \mathrm{C}$ for 3 min leads to the production of $\alpha$-phase $\mathrm{Alq}_{3}$, in a similar manner as the boehmite and aluminum hydroxide, after $1 \mathrm{~h}$ and $24 \mathrm{~h}$, respectively. These findings suggest that the precursor of aluminum has little effect on the formation of the crystalline phases and/or isomers of $\mathrm{Alq}_{3}$ but that the reaction time is an important factor for inducing the isomerization reaction.

To spectroscopically confirm the phase of $\mathrm{Alq}_{3}$, PL spectra were measured for the microbelts formed on APA surfaces prepared under both anodizing conditions (Figure 4). PL peaks can be observed at around $520 \mathrm{~nm}$, agreeing with the previous results for $\alpha$-Alq $\mathrm{q}_{3}$ made up of the meridional isomer $[2,4]$. The results of the XRD and PL studies lead us to conclude that the microbelts consist of the $\alpha$-phase of $\mathrm{Alq}_{3}$ without depending on the anodization processes.

3.2. SEM Observation of $\mathrm{Alq}_{3}$ on APA Surface. Figure 5 shows SEM images of the as-prepared one-step APA sample and the samples treated in the HQ solutions of different concentrations at $100^{\circ} \mathrm{C}$ for $10 \mathrm{~min}$. A rough surface with splinters and cracks is observed on the as-prepared surface (a). With the $1 \mathrm{mM}$ HQ solution (b), the surface becomes smoother than that of (a). Although no crystals can be observed on the surface, green fluorescence was observed when the surface was irradiated with ultraviolet light. These results suggest that, with this concentration, the APA surface reacts with the $\mathrm{HQ}$. The $\mathrm{Alq}_{3}$ microbelts appear with the $3 \mathrm{mM}$ HQ solution (c) and further increase with the HQ concentration, as shown in (d)-(f).

Figure 6 shows the PL spectra for the APA samples shown in Figure 5. The PL peak of the as-prepared APA sample (a) exhibits a peak at around $450 \mathrm{~nm}$ due to APA defects [29]. At $1 \mathrm{mM}$ (b), the PL spectrum shows two peaks at 473 and $505 \mathrm{~nm}$, which are the same results found in our previous study of APA treated in $\mathrm{HQ}$ in $\mathrm{EtOH}$ at $60^{\circ} \mathrm{C}$ [27]. The former and latter peaks are assigned to the isolated $\mathrm{Alq}_{3}$ species in nanovoids, while the aggregated $\mathrm{Alq}_{3}$ species are assigned to the nanopores in the APA. Given the similarity of the surfaces and the spectra, we believe that the entrapped states of the $\mathrm{Alq}_{3}$ on the APA of (b) are almost identical to those treated in $\mathrm{HQ}$ in $\mathrm{EtOH}$ at $60^{\circ} \mathrm{C}$. Above $3 \mathrm{mM}$ HQ (c)-(f), the PL peaks were observed at around $520 \mathrm{~nm}$ due to the microbelts assigned to the $\alpha-\mathrm{Alq}_{3}$ phase, discussed above.

Figure 7 shows SEM images of the one-step APA samples treated in a $10 \mathrm{mM} \mathrm{HQ}$ solution at $100^{\circ} \mathrm{C}$ for different dipping times. When the sample was dipped into the solution and immediately removed, nanosized particles with a diameter of $300-400 \mathrm{~nm}$ formed (a), as were a very small number of microbelts with lengths of less than $5 \mu \mathrm{m}$ and widths less than $3 \mu \mathrm{m}$ (b). We observed many more particles than microbelts. Thus, it would appear that the nanoparticles aggregate into microbelts. At $10 \mathrm{~s}$ (c), the microbelts start to self-assemble into flower-like structures. Then, the microbelts grew rapidly with time, such that the APA surface was covered with microbelts at $60 \mathrm{~s}$ (d). Between $180 \mathrm{~s} \mathrm{(e)} \mathrm{and}$ $300 \mathrm{~s}$ (f), no increase in the size was observed. However, the surface of the microbelts formed at $300 \mathrm{~s}$ appears somewhat disordered.

Figure 8 shows SEM images of the one-step APA samples treated in $10 \mathrm{mM}$ HQ solutions at different temperatures. At around $30^{\circ} \mathrm{C}(\mathrm{a})$, there are protruding crystals with a diameter of about $1-2 \mu \mathrm{m}$ on the surface, which may be sprouts from the $\mathrm{Alq}_{3}$ crystals. Above $60^{\circ} \mathrm{C}(\mathrm{b})-(\mathrm{d})$, the flowerlike structures can be clearly observed. This temperature dependence gives us some valuable insight. The $\mathrm{Alq}_{3}$ crystals formed in the aqueous $\mathrm{HQ}$ solution at $60^{\circ} \mathrm{C}$, while no crystals were observed on the APA treated in a solution of HQ in $\mathrm{EtOH}$. This difference is probably caused by the low solubility of $\mathrm{Alq}_{3}$ in water and the large reactivity of HQ with APA in water, relative to that in $\mathrm{EtOH}$.

Another important point is that the $\mathrm{Alq}_{3}$ crystals form at $60^{\circ} \mathrm{C}$. In general, the surface of APA is considered to be amorphous $\mathrm{Al}_{2} \mathrm{O}_{3}$ [30], which changes to a boehmite layer as a result of the treatment of the APA in water above $90^{\circ} \mathrm{C}$ [31]. The results of the present study indicate that the microbelts are produced by the reaction between the HQ and amorphous $\mathrm{Al}_{2} \mathrm{O}_{3}$ species of the APA without a boehmite layer. 


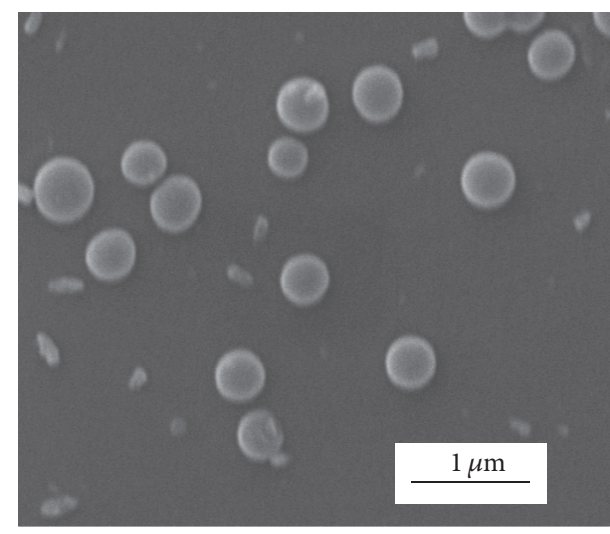

(a)

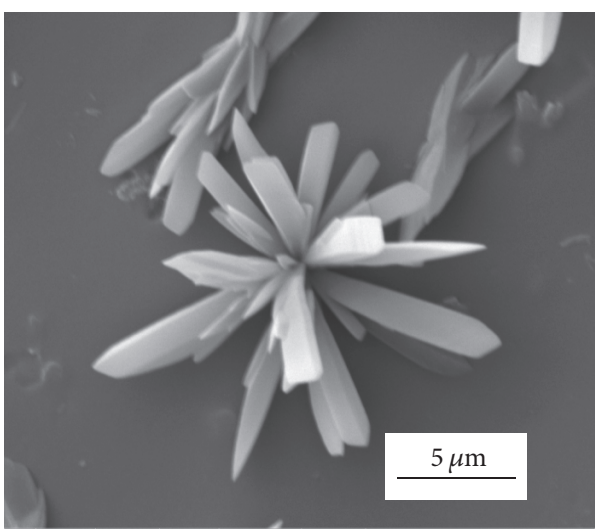

(c)

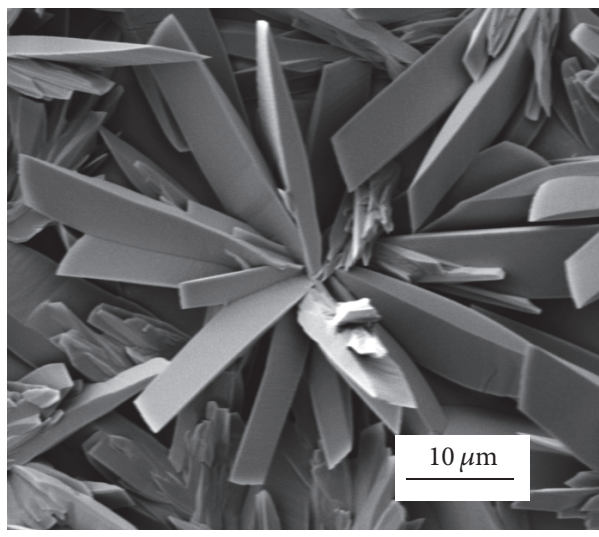

(e)

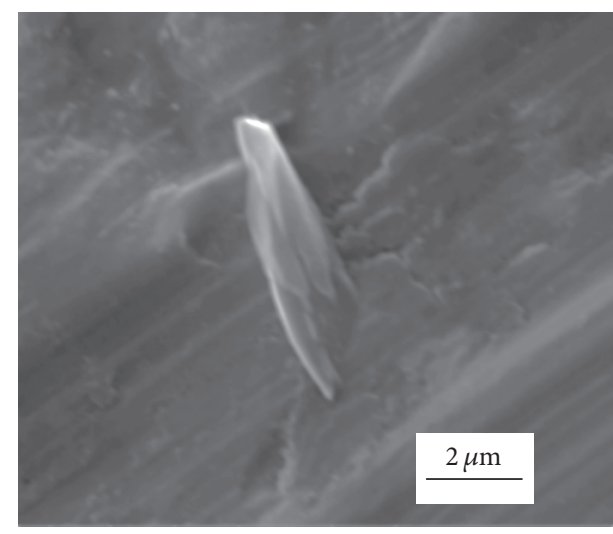

(b)

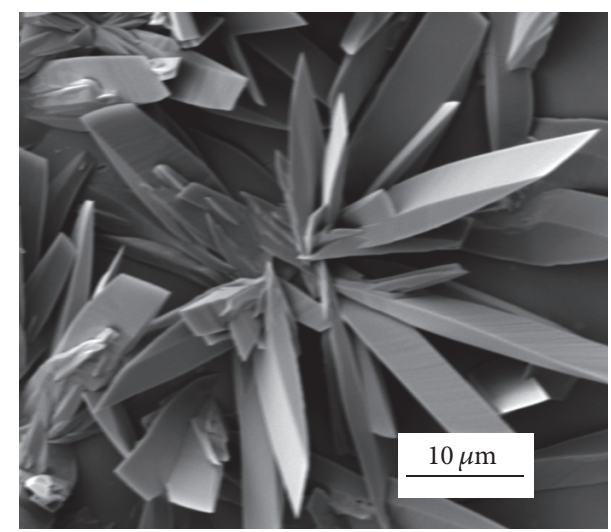

(d)

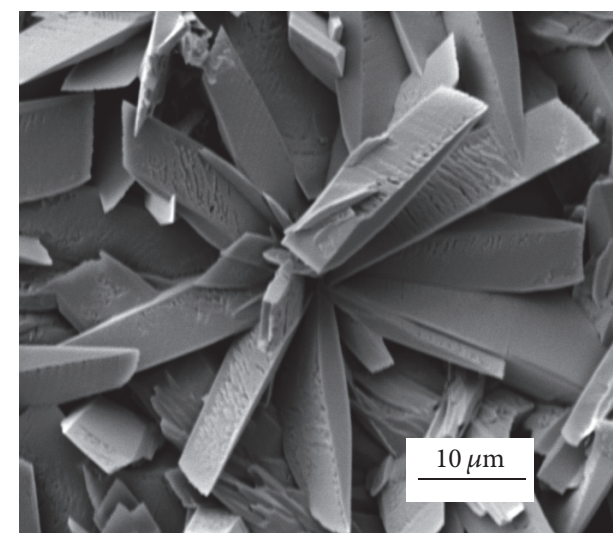

(f)

FIGURE 7: SEM images of $\mathrm{Alq}_{3}$ growth on the one-step APA samples, observed after different dipping times: dipping alone (a) and (b); $10 \mathrm{~s}$ (c); $60 \mathrm{~s} \mathrm{(d);} 180 \mathrm{~s}(\mathrm{e})$; and $300 \mathrm{~s}$ (f). Images (a) and (b) were observed at different locations on the same sample.

3.3. Growth Mechanism of $\mathrm{Alq}_{3}$ Flower-Like Structure. We considered the growth steps of the $\mathrm{Alq}_{3}$ crystals formed from the HQ species, based on the sizes of the crystals observed in time-dependence studies (Figures 7(a)-7(c)): nanoparticles, belt-like structures, and flower-like structures. These steps appear to be similar to those of the sonochemical fabrication of $\mathrm{Alq}_{3}$ nanoflowers reported by Mao et al. [18] attributed to cavitation and an Ostwald ripening process.

We propose that the mechanism for evolution of the flower-like crystal morphologies observed in our study can be explained by Ostwald ripening (Figure 9); (1) the nanoparticles of $\mathrm{Alq}_{3}$ are formed on the APA surface as a result of the reaction of the $\mathrm{HQ},(2)$ then the precipitated particles grow to form microbelts due to the aggregation of the nanoparticles, and (3) the individual microbelts assemble into flower-like structures.

Figure 10 shows cross-sectional SEM images (a) EDX mapping of the $\mathrm{Alq}_{3}$ microbelts on the two-step APA and (b) EDX spectra observed in regions I, II, and III. Region I only exhibits a peak for elemental $\mathrm{Al}$, since it is detecting 


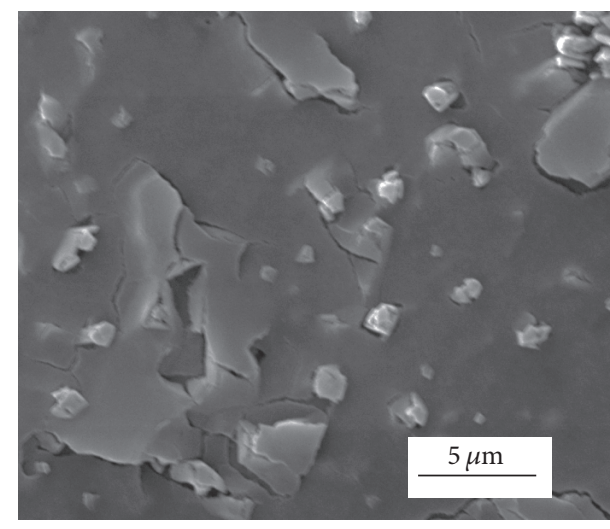

(a)

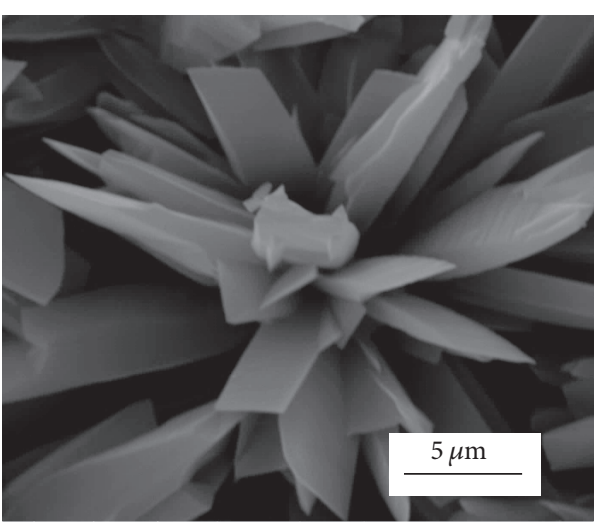

(c)

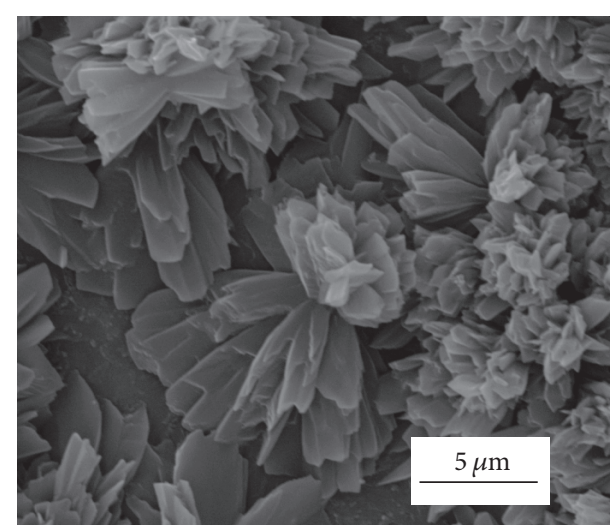

(b)

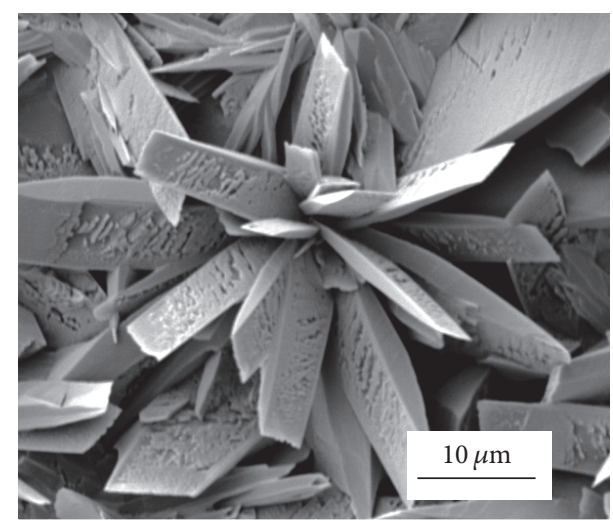

(d)

FIGURE 8: SEM images of $\mathrm{Alq}_{3}$ crystals formed on one-step APA samples treated in $10 \mathrm{mM}$ HQ solution for 10 min at different temperatures: $30^{\circ} \mathrm{C}(\mathrm{a}) ; 60^{\circ} \mathrm{C}(\mathrm{b}) ; 80^{\circ} \mathrm{C}(\mathrm{c}) ;$ and $100^{\circ} \mathrm{C}(\mathrm{d})$.

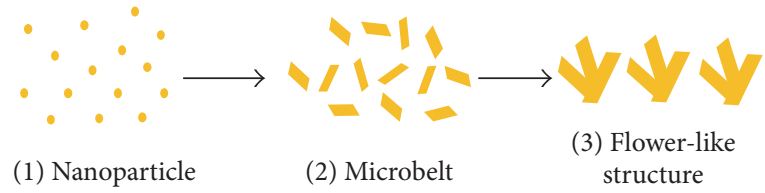

FIGURE 9: Scheme of $\mathrm{Alq}_{3}$ growth from nanoparticles to flower-like structures. Illustrations (1), (2), and (3) correspond to the SEM images of Figures $7(\mathrm{a}), 7(\mathrm{~b})$, and $7(\mathrm{c})$, respectively.

the original Al plate (a). Region II shows peaks for elemental $\mathrm{O}$ and $\mathrm{Al}(\mathrm{d})$, which is expected for the $\mathrm{Al}_{2} \mathrm{O}_{3}$ layer. On the other hand, $\mathrm{C}, \mathrm{N}, \mathrm{O}$, and $\mathrm{Al}$ elements are only observed on the crystal surface, in region III, as shown in (e), suggesting that the $\mathrm{Alq}_{3}$ crystals exist mainly on the surface of the $\mathrm{Al}_{2} \mathrm{O}_{3}$. These results indicate that the formation of $\mathrm{Alq}_{3}$ occurs at the interface between the oxide film surface and the HQ solution.

\section{Conclusion}

Crystalline $\mathrm{Alq}_{3}$ microbelts, about 5-10 $\mu \mathrm{m}$ wide and 5-20 $\mu \mathrm{m}$ long, were formed on an APA surface treated in heated water containing HQ. The microbelts self-assembled into flower-like structures. The structure of the $\mathrm{Alq}_{3}$ microbelts is attributed to the $\alpha$-phase, given the results obtained from XRD studies. These findings suggest that the precursor of aluminum has little effect on the formation of the crystalline phases and/or isomers of $\mathrm{Alq}_{3}$ but that the reaction time is an important factor for inducing the isomerization reaction. The green photoluminescence of the $\mathrm{Alq}_{3}$ microbelts peaks at around $520 \mathrm{~nm}$. The crystalline phase and photoluminescence center of the $\mathrm{Alq}_{3}$ were formed on the APA independently of the anodization processes (i.e., one- or two-step anodization). The formation of the $\mathrm{Alq}_{3}$ species was induced by the reaction of the HQ species and amorphous $\mathrm{Al}_{2} \mathrm{O}_{3}$ species at the interface between the HQ solution and APA surface. The flower-like structures grew from the nanoparticles after first forming into microbelts, most likely due to Ostwald ripening. The results of the present study will provide a basis for devising further 


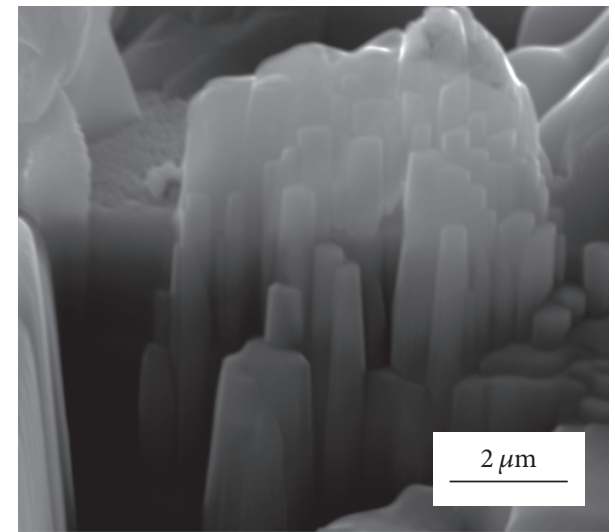

(a)

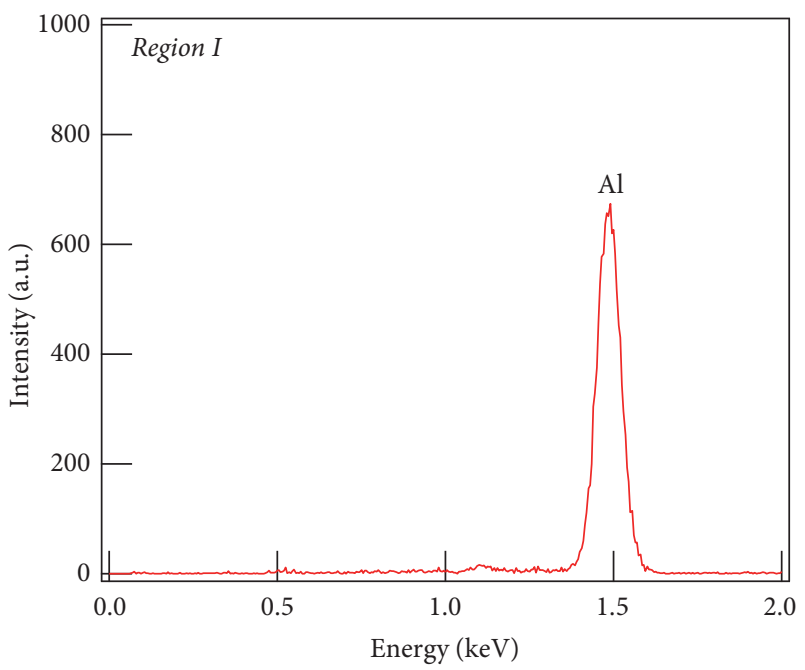

(c)

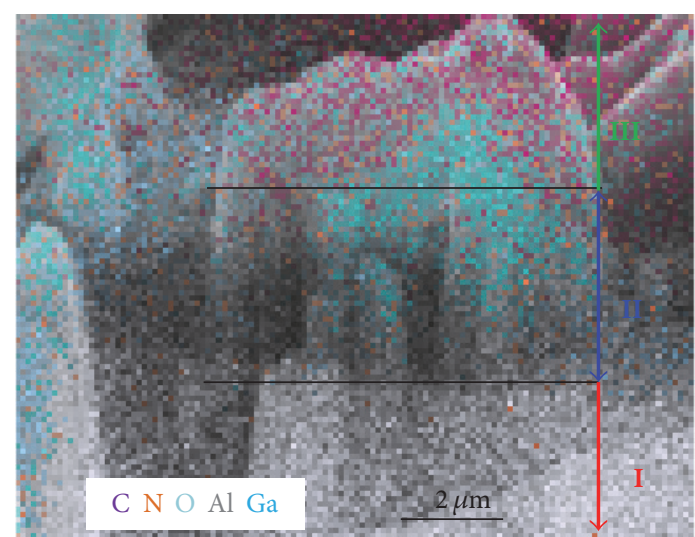

(b)

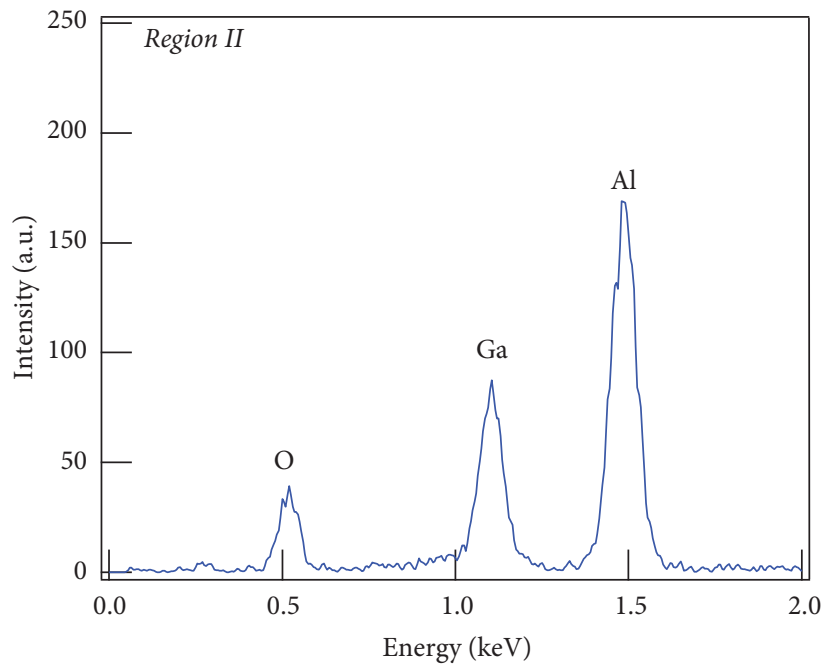

(d)

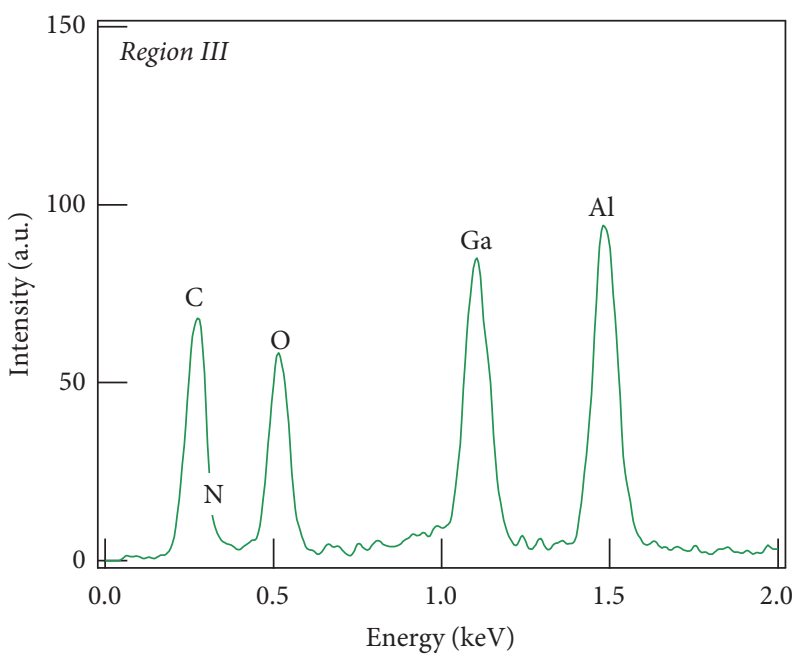

(e)

FIGURE 10: Cross-sectional SEM image (a) and EDX mapping of $\mathrm{Alq}_{3}$ microbelts on the two-step APA (b), and EDX spectra (c) to (e), observed in different regions. 
methods for preparing $\mathrm{Alq}_{3}$. To further investigate how $\mathrm{Alq}_{3}$ affects optoelectronic properties, we plan to prepare a facial isomer in the surface reaction of APA.

\section{Conflicts of Interest}

The authors declare that they have no conflicts of interest.

\section{Acknowledgments}

This research was funded by the MEXT-Supported Program for the Strategic Research Foundation at Private Universities, 2015-2016.

\section{References}

[1] C. W. Tang and S. A. Van Slyke, "Organic electroluminescent diodes," Applied Physics Letters, vol. 51, no. 12, pp. 913-915, 1987.

[2] M. Brinkmann, G. Gadret, M. Muccini, C. Taliani, N. Masciocchi, and A. Sironi, "Correlation between molecular packing and optical properties in different crystalline polymorphs and amorphous thin films of mer-tris(8hydroxyquinoline)aluminum(III)," Journal of the American Chemical Society, vol. 122, no. 1, pp. 5147-5157, 2000.

[3] W. Xie, Z. Pang, Y. Zhao et al., "Structural and optical properties of $\varepsilon$-phase tris(8-hydroxyquinoline) aluminum crystals prepared by using physical vapor deposition method," Journal of Crystal Growth, vol. 404, pp. 164-167, 2014.

[4] M. Braun, J. Gmeiner, M. Tzolov et al., "A new crystalline phase of the electroluminescent material tris(8-hydroxyquinoline) aluminum exhibiting blueshifted fluorescence," Journal of Chemical Physics, vol. 114, no. 21, pp. 9625-9632, 2001.

[5] M. Cölle, R. E. Dinnebier, and W. Brütting, "The structure of the blue luminescentd $\delta$-phase of tris(8-hydroxyquinoline)aluminium(III) $\left(\mathrm{Alq}_{3}\right)$," Chemical Communications, no. 23, pp. 2908-2909, 2002.

[6] M. Cölle, J. Gmeiner, W. Milius, H. Hillebrecht, and W. Brütting, "Preparation and characterization of blue-luminescent tris(8hydroxyquinoline)aluminum $\left(\mathrm{Alq}_{3}\right)$, , Advanced Functional Materials, vol. 13, no. 2, pp. 108-112, 2003.

[7] M. Muccini, M. A. Loi, K. Kenevey, R. Zamboni, N. Masciocchi, and A. Sironi, "Blue luminescence of facial tris(quinolin8-olato)aluminum(III) in solution, crystals, and thin films," Advanced Materials, vol. 16, no. 11, pp. 861-864, 2004.

[8] H. Kaji, Y. Kusaka, G. Onoyama, and F. Horii, "Relationships between light-emitting properties and different isomers in polymorphs of tris(8-hydroxyquinoline) aluminum(III) $\left(\mathrm{Alq}_{3}\right)$ analyzed by solid-state ${ }^{27} \mathrm{Al} \mathrm{NMR}$ and Density Functional Theory (DFT) calculations," Japanese Journal of Applied Physics, Part 1: Regular Papers and Short Notes and Review Papers, vol. 44, no. 6, pp. 3706-3711, 2005.

[9] M. Rajeswaran, T. N. Blanton, R. H. Young, and W. Brennessel, "Modeling disorder in the crystal structure of the $\alpha$ polymorph of $\mathrm{Alq}_{3}$," Journal of Chemical Crystallography, vol. 40, no. 3, pp. 195-200, 2010.

[10] R. Katakura and Y. Koide, "Configuration-specific synthesis of the facial and meridional isomers of tris(8-hydroxyquinolinate)aluminum $\left(\mathrm{Alq}_{3}\right)$," Inorganic Chemistry, vol. 45, no. 15 , pp. 5730-5732, 2006.
[11] M. Rajeswaran and T. N. Blanton, "Single-crystal structure determination of a new polymorph $\left(\varepsilon-\mathrm{Alq}_{3}\right)$ of the electroluminescence OLED (organic light-emitting diode) material, tris $(8$ hydroxyquinoline)aluminum $\left(\mathrm{Alq}_{3}\right)$," Journal of Chemical Crystallography, vol. 35, no. 1, pp. 71-76, 2005.

[12] H. Kaji, Y. Kusaka, G. Onoyama, and F. Horii, "CP/MAS ${ }^{13} \mathrm{C}$ NMR characterization of the isomeric states and intermolecular packing in tris(8-hydroxyquinoline) aluminum(III) ( $\left.\mathrm{Alq}_{3}\right)$," Journal of the American Chemical Society, vol. 128, no. 13, pp. 4292-4297, 2006.

[13] M. Rajeswaran, T. N. Blanton, C. W. Tang et al., "Structural, thermal, and spectral characterization of the different crystalline forms of $\mathrm{Alq}_{3}$, tris(quinolin-8-olato)aluminum(III), an electroluminescent material in OLED technology," Polyhedron, vol. 28, pp. 835-843, 2009.

[14] J.-J. Chiu, W.-S. Wang, C.-C. Kei, and T.-P. Perng, “Tris-(8hydroxyquinoline) aluminum nanoparticles prepared by vapor condensation," Applied Physics Letters, vol. 83, no. 2, pp. 347349, 2003.

[15] C. P. Cho, C. A. Wu, and T. P. Peng, "Crystallization of amorphous tris(8-hydroxyquinoline)aluminum nanoparticles and transformation to nanowires," Advanced Functional Materials, vol. 16, pp. 819-823, 2006.

[16] Y. S. Zhao, C. Di, W. Yang, G. Yu, Y. Liu, and J. Yao, "Photoluminescence and electroluminescence from tris(8hydroxyquinoline)aluminum nanowires prepared by adsorbent-assisted physical vapor deposition," Advanced Functional Materials, vol. 16, no. 15, pp. 1985-1991, 2006.

[17] J.-S. Hu, H.-X. Ji, A.-M. Cao et al., "Facile solution synthesis of hexagonal $\mathrm{Alq}_{3}$ nanorods and their field emission properties," Chemical Communications, no. 29, pp. 3083-3085, 2007.

[18] C. J. Mao, D. C. Wang, H. C. Pan, and J. J. Zhu, "Sonochemical fabrication of 8-hydroxyquinoline aluminum $\left(\mathrm{Alq}_{3}\right)$ nanoflowers with high electrogenerated chemiluminescence," Ultrasonics Sonochemistry, vol. 18, pp. 473-476, 2011.

[19] M. M. El-Nahass, A. M. Farid, and A. A. Atta, "Structural and optical properties of Tris(8-hydroxyquinoline) aluminum (III) $\left(\mathrm{Alq}_{3}\right)$ thermal evaporated thin films," Journal of Alloys and Compounds, vol. 507, no. 1, pp. 112-119, 2010.

[20] F. Suzuki, Y. Nishiyama, and H. Kaji, "Clarification of isomeric structures and the effect of intermolecular interactions in blueemitting aluminum complex $\mathrm{Alq}_{3}$ using first-principles ${ }^{27} \mathrm{Al}$ NMR calculations," Chemical Physics Letters, vol. 605-606, pp. $1-4,2014$.

[21] A. V. Kukhta, G. G. Gorokh, E. E. Kolesnik et al., "Nanostructured alumina as a cathode of organic light-emitting devices," Surface Science, vol. 507-510, pp. 593-597, 2002.

[22] C. Xu, Q. Xue, L. Ba, B. Zhao, N. Gu, and Y. Cui, "Spectral behavior of 8-hydroxyquinoline aluminum in nanometer-sized holes of porous alumina," Chinese Science Bulletin, vol. 46, no. 21, pp. 1839-1841, 2001.

[23] C. Xu, Q. Xue, Y. Zhong et al., "Photoluminescent blue-shift of organic molecules in nanometre pores," Nanotechnology, vol.13, no. 1, pp. 47-50, 2002.

[24] I. Miura, Y. Okada, S. Kudoh, and M. Nakata, "Organic electroluminescence in porous alumina," Japanese Journal of Applied Physics, Part 1: Regular Papers and Short Notes and Review Papers, vol. 43, no. 11, pp. 7552-7553, 2004.

[25] G. S. Huang, X. L. Wu, Y. Xie et al., "Photoluminescence from 8-hydroxyquinoline aluminum embedded in porous anodic alumina membrane," Applied Physics Letters, vol. 87, Article ID 151910, 2005. 
[26] A. Mohammadpour, I. Utkin, S. C. Bodepudi et al., "Photophysics and energy transfer studies of $\mathrm{Alq}_{3}$ confined in the voids of nanoporous anodic alumina," Journal of Nanoscience and Nanotechnology, vol. 13, no. 4, pp. 2647-2655, 2013.

[27] S. Yamaguchi and K. Matsui, "Formation and Entrapment of tris(8-hydroxyquinoline)aluminum from 8-hydroxyquinoline in anodic porous alumina," Materials, vol. 9, p. 715, 2016.

[28] T. Tsuboi and Y. Torii, "Selective synthesis of facial and meridianal isomers of $\mathrm{Alq}_{3}$," Molecular Crystals and Liquid Crystals, vol. 529, pp. 42-52, 2010.

[29] G. S. Huang, X. L. Wu, G. G. Siu, and P. K. Chu, "On the origin of light emission from porous anodic alumina formed in sulfuric acid," Solid State Communications, vol. 137, no. 11, pp. 621-624, 2006.

[30] V. P. Parkhutik, V. T. Belov, and M. A. Chernyckh, "Study of aluminium anodization in sulphuric and chromic acid solutions-II. Oxide morphology and structure," Electrochimica Acta, vol. 35, no. 6, pp. 961-966, 1990.

[31] J. W. Diggle, T. C. Downie, and C. W. Goulding, "Anodic oxide films on aluminum," Chemical Reviews, vol. 69, no. 3, pp. 365405, 1969. 

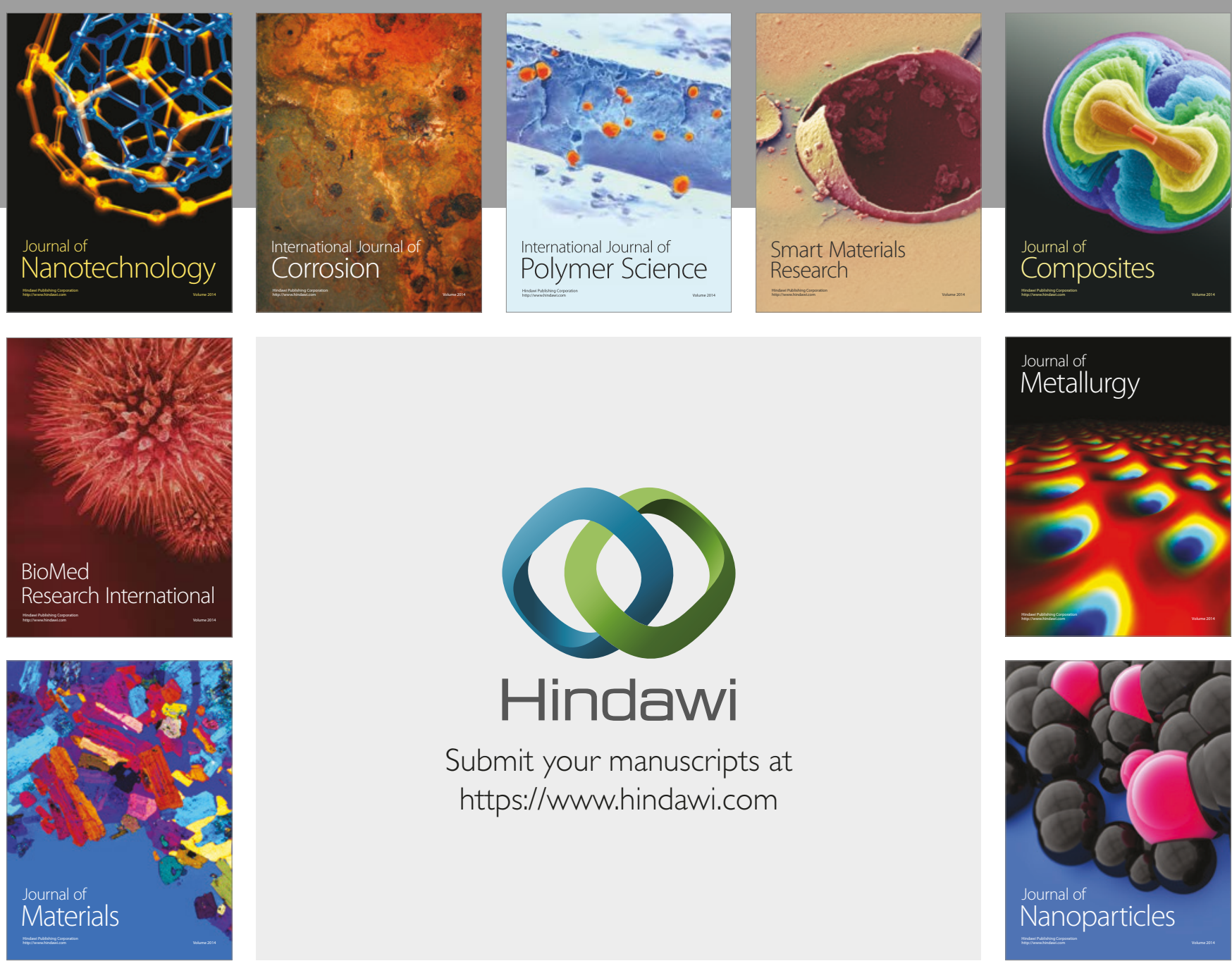

\section{Hindawi}

Submit your manuscripts at

https://www.hindawi.com
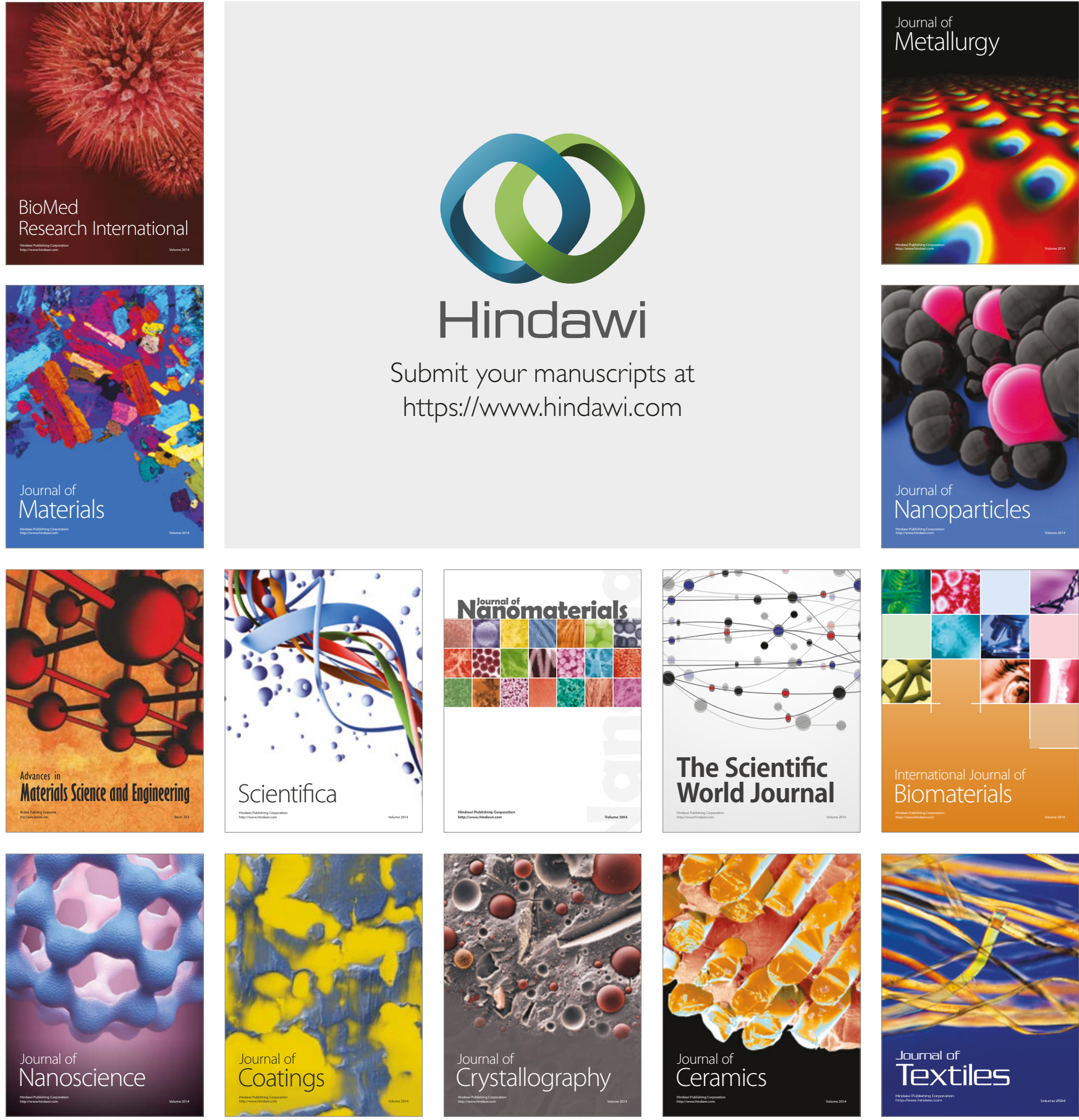

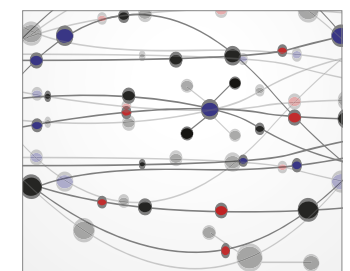

The Scientific World Journal
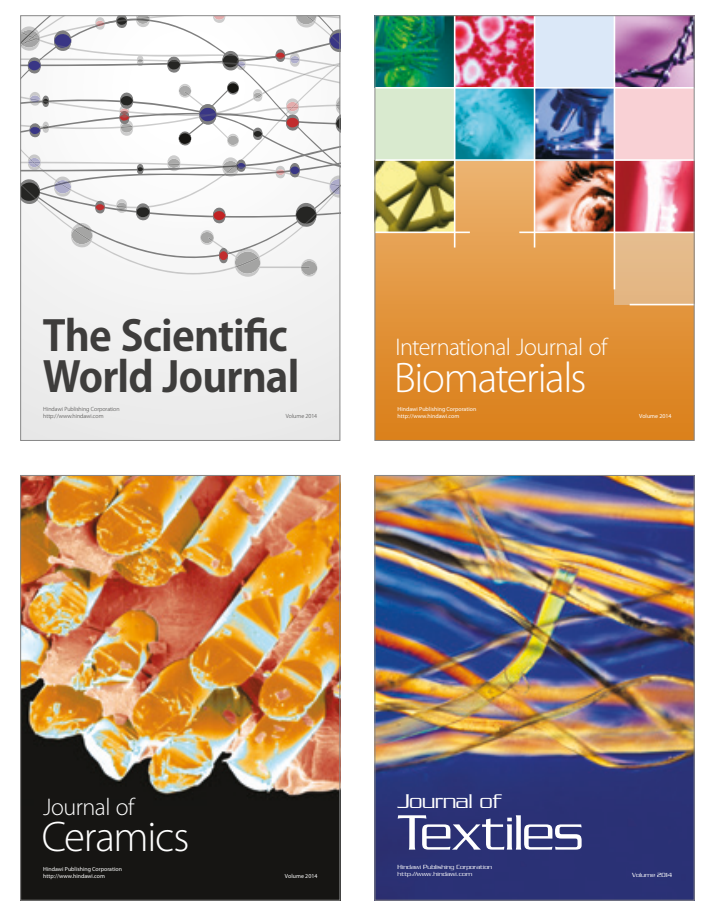